\title{
Synthesis of aminated polystyrene and its self- assembly with nanoparticles at oil/water interface
}

Chenliang Shi ${ }^{1}$, Yukun Yang ${ }^{1}$, Ling Lin ${ }^{1,2}$ *, Wenjia Luo ${ }^{1}$, Maoqing Deng ${ }^{1}$, Pingya Luo ${ }^{3}$, Yujie $W u^{1}$

Affiliation 1: School of Chemistry and Chemical Engineering, Southwest Petroleum University, Chengdu, Sichuan Province 610500, China; e-mail:

chenliang.shi@aliyun.com (C.S); ykforce@outlook.com; cowbolinling@aliyun.com

(L.L); dengmaoqing@163.com (M.D); luowenjia@swpu.edu.cn (W.L);

wyj996688@aliyun.com (Y.J).

Affiliation 2: Oil \& Gas Field Applied Chemistry Key Laboratory of Sichuan Province (Southwest Petroleum University), Chengdu, Sichuan Province 610500; e-mail: cowbolinling@aliyun.com (L.L)

Affiliation 3: State Key Laboratory of Oil and Gas Reservoir Geology and Exploitation, Chengdu, Sichuan Province 610500; e-mail: luopy@ swpu.edu.cn (P.L)

Abstract

Nanoparticle (NP)-surfactants formed by the self-assembly of NPs and endfunctionalized polymers at the hydrophilic/hydrophobic interface have a wide range of 
applications in many fields. In this study, the influence of density of amino groups, NPs dimension and $\mathrm{pH}$ on the interaction between end-functionalized polymers and NPs were extensively investigated. Single amino-terminated polystyrene $\left(\mathrm{PS}-\mathrm{NH}_{2}, M_{w} \approx\right.$ $0.6 \mathrm{k}, 2.5 \mathrm{k}, 3.5 \mathrm{k}, 3.9 \mathrm{k})$ and diamino-terminated polystyrene $\left(\mathrm{H}_{2} \mathrm{~N}-\mathrm{PS}-\mathrm{NH}_{2}, M_{w} \approx 1.1 \mathrm{k}\right.$, $2.8 \mathrm{k}$ ) were prepared using reversible addition-fragmentation chain transfer polymerization and atom transfer radical polymerization. NPs with different dimensions (zero-dimensional carbon dots with sulfonate groups, one-dimensional cellulose nanocrystals with sulfate groups and two-dimensional graphene with sulfonate groups) in the aqueous phase were added into the toluene phase containing the aminated PS. The influence of $\mathrm{pH}$ and the molecular weight of amino-terminated PS on the interfacial tension between two phases were investigated. The results indicate that aminated PS exhibited the strongest interfacial activity after compounding with sulfonated NPs at a pH of 3. Terminating PS with amino groups on both ends leads to better performance in in reducing the water/toluene interfacial tension than modifying the molecular structure of PS on a single end. The dimension of sulfonated NPs also contributed significantly to the reduction of the water/toluene interfacial tension. The minimal interfacial tension was $4.49 \mathrm{mN} / \mathrm{m}$ after compounding $\mathrm{PS}-\mathrm{NH}_{2}$ with sulfonated zero-dimensional carbon dots. Molecular dynamics simulation on the evolution of the water/toluene interface in the presence of sulfonated carbon dots and $\mathrm{H}_{2} \mathrm{~N}-\mathrm{PS}-\mathrm{NH}_{2}$ revealed that these opposite charged substances moved towards the interface in an extreme short time and orderly assembled in a thermodynamic equilibrium.

Keywords: Aminated polystyrene, Nanoparticles, Interfacial tension, Self-assembly 


\section{Introduction}

Nanoparticles (NPs) with a responsive behavior to external forces, e.g. magnetic fields ${ }^{[1]}$, electric fields ${ }^{[2]}$ and ultraviolet radiation ${ }^{[3]}$, have been widely studied for their ability of self-assembly at oil/water $(\mathrm{O} / \mathrm{W})$ interfaces. It was also found that the formulation of NPs and end-functionalized polymers, which can be individually used as surfactants, can strengthen the $\mathrm{O} / \mathrm{W}$ interfacial activity ${ }^{[4]}$ by forming complex NPs/surfactants structures driven by electrostatic structures. The orderly assembly of $\mathrm{NPs} /$ surfactants at $\mathrm{O} / \mathrm{W}$ interface improve the compatibility between the $\mathrm{O} / \mathrm{W}$ phases, allowing promising applications in fields including medical pharmaceuticals ${ }^{[5]}$, food $\operatorname{processing}^{[6]}$, enhanced oil recovery ${ }^{[7]}$, and inkjet printing ${ }^{[8]}$.

The $\mathrm{O} / \mathrm{W}$ interfacial energy can be regulated by the $\mathrm{pH}$ of the aqueous solution, the molecular weight, the concentration of the end-functionalized polymer and the external electric field ${ }^{[9]}$. Huang et al. ${ }^{[10]}$ investigated the effect of $\mathrm{pH}$ on the in situ formation of NPs (carboxylated polystyrene, PS-COOH)/surfactants (aminated polydimethylsiloxane, PDMS-NH 2 ) and found an optimal $\mathrm{pH}$ of 4.66. Liu et al. ${ }^{[4]}$ used CNCs and PS-NH $2\left(M_{w}=1.5 \mathrm{k}, 2.5 \mathrm{k}, 13 \mathrm{k}, 25 \mathrm{k}, 40 \mathrm{k}\right)$ as NPs in water and as the surfactant in toluene, respectively, and reached the conclusion that the molecular weight of $\mathrm{PS}-\mathrm{NH}_{2}$ exerted a considerable influence on the interfacial behavior of NPs/surfactants. When $M_{w}=1.5 \mathrm{k}, \mathrm{PS}_{\mathrm{NH}}$, interacting with $\mathrm{CNCs}$, reduced the $\mathrm{O} / \mathrm{W}$ interfacial tension to below $7 \mathrm{mN} / \mathrm{m}$. As the $M_{w}$ increased, the interfacial activity of NPs/surfactants decreased; the $\mathrm{O} / \mathrm{W}$ interface was seldom affected when the $M_{w}$ was 
higher than $25 \mathrm{k}$. The molecular weight of $\mathrm{PS}-\mathrm{NH}_{2}$ also influenced the formation

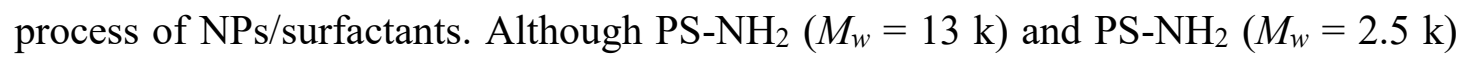
exhibited a similar ability to reduce the $\mathrm{O} / \mathrm{W}$ interfacial tension in the presence of $\mathrm{CNCs}$, it took a longer time for the former/CNCs to reach interfacial equilibrium. The assembly of carboxylated $\mathrm{SiO}_{2}$ as NPs in water and PDMS-NH $\mathrm{N}_{2}$ as the surfactant in silicon oil also reduced the $\mathrm{O} / \mathrm{W}$ interfacial tension, according to Chai et al ${ }^{[11]}$. The introduction of salt increased the ionic strength of water and further decreased the $\mathrm{O} / \mathrm{W}$ interfacial tension. The observation of high-speed image analysis experiments indicated that the addition of $\mathrm{NaCl}$ enhanced the packing density of NPs at the $\mathrm{O} / \mathrm{W}$ interface and therefore improved the assembly of NPs/surfactants. Toor et al. ${ }^{[12]}$ used carboxylated silica as NPs in water and PDMS-NH 2 as surfactants in N,N-Dimethylformamide (DMF) to investigate the effect of polymer concentration on the interfacial properties. The polar/nonpolar interfacial activity of NPs/surfactants benefited from the increase in polymer concentration, and the interfacial tension was reduced to $10 \mathrm{mN} / \mathrm{m}$. They also demonstrated that $\mathrm{PDMS}-\mathrm{NH}_{2}$ exhibited little interfacial activation in the absence of carboxylated NPs ${ }^{[13]}$. Cui et al. ${ }^{[14]}$ used PS-COOH as NPs in water and PDMS-NH 2 in the silicone oil as the surfactants. By analyzing the shape of the droplets, the authors revealed the formation process of NPs/surfactants at the $\mathrm{O} / \mathrm{W}$ interface in an external electric field, including the diffusion of NPs and surfactants to the O/W interface as well as the electrostatic interaction mechanism.

The above research achieved a considerable reduction in $\mathrm{O} / \mathrm{W}$ interfacial tension via a series of methods. Most of the end-functionalized polymers reported in these papers 
were aminated. Adjusting the $\mathrm{pH}$ of water had a profound influence on both the protonation of amino groups and the electrostatic interaction between oppositely charged groups of NPs and polymers. However, the effect of two terminal functionalized polymers on the assembly of NPs/surfactants, and the relationship between the dimension of NPs and the interaction between NPs and end-functionalized polymers are not discussed in the previous papers. In addition, to the best knowledge of the authors, little research has been done on the simulation of the arrangement of NPs/surfactants in the $\mathrm{O} / \mathrm{W}$ interface.

To reveal the influence of the number of amino groups in end-functionalized polymers and the dimensional of NPs, two kinds of aminated PS and three kinds of NPs (zero-dimensional sulfonated carbon dots $\left(\mathrm{CDs}-\mathrm{SO}_{3} \mathrm{H}\right)$ ), one-dimensional sulfated cellulose nanocrystals $\left(\mathrm{CNCs}-\mathrm{OSO}_{3} \mathrm{H}\right)$, and two-dimensional sulfonated graphene oxides $\left(\mathrm{GOs}-\mathrm{SO}_{3} \mathrm{H}\right)$ were used to test the $\mathrm{O} / \mathrm{W}$ interfacial tension in this study. Molecular simulations on the interaction between aminated PS and sulfonated carbon dots were also carried out to reveal the assembly of NPs/surfactants at the O/W interface.

\section{Materials and Methods}

\subsection{Sample Preparation}

Triethylamine, 1-butanethiol, N-(bromomethyl)phthalimide, tributylstannane, potassium phthalimide, 2,2'-bipyridine, citric acid and sulfanilic acid were purchased from TCI and used as received. Copper (I) bromide was obtained from Aldrich and was purified by stirring in acetic acid, washed with ethanol and then stored in argon. Aladdin 
provided 2,2-azobis(2-methylpropionitrile) (AIBN), which was recrystallized twice from methanol. Carbon disulfide and chloroform were purchased from Aladdin and distilled three times. Styrene from Aladdin was passed through basic alumina (100-200 mesh) to remove inhibitors. Sulfonated CNCs (diameter of 5-20 nm, length of 100-200 $\mathrm{nm}$ ) in aqueous solutions and $\mathrm{GOs}-\mathrm{SO}_{3} \mathrm{H}$ (diameter of 1.2-4.0 $\mu \mathrm{m}$, thickness of 0.8-6.6 nm) were obtained from Shanghai ScienceK Nanotechnology Co., LtD (China) and Shandong Jincheng Graphene Technology Co., LtD (China), respectively. Other agents were purchased from Aladdin and used as received.

\subsection{Synthesis}

2.2.1 Synthesis of $\mathrm{PS}-\mathrm{NH}_{2}$ by reversible addition-fragmentation chain transfer polymerization (RAFT)

\section{Synthesis of chain transfer agent (1)}

The compound was synthesized following the procedures reported by Postma ${ }^{[15] .} \mathrm{A}$ mixture of carbon disulfide (6.07 g) and 1-butanethiol (3.57 g) in chloroform (25 mL) was prepared with stirring, and triethylamine $(8.21 \mathrm{~g})$ was then added. The reaction lasted for $3 \mathrm{~h}$ at room temperature, and $\mathrm{N}$-(bromomethyl)phthalimide (9.59 g) was then added in portions over $0.5 \mathrm{~h}$. The mixture was stirred at room temperature for $16 \mathrm{~h}$. Chloroform $(20 \mathrm{~mL})$ was added and the organic layers were washed successively with water, $\mathrm{H}_{2} \mathrm{SO}_{4}$, water and brine. Then, the organic layers were dried over magnesium sulfate, and the solvent was subsequently filtered and removed to provide a crude solid that was crystallized from methanol. Yield $=11.87 \mathrm{~g}(88.28 \%)$. 
Styrene (30.12 g), chain transfer agent 1 (2.92 g) and AIBN (1.71 g) were added into a three-neck flask. The flask was sealed and pumped to vacuum $\left(=10^{-3}\right.$ Torr $)$, and the mixture was purged with argon for $30 \mathrm{~min}$. The mixture was stirred at $60{ }^{\circ} \mathrm{C}$ for various durations $(4,8,12,24 \mathrm{~h})$. After the reaction, the mixture was cooled to room temperature and added to methanol to obtain yellowish modified PS. The ${ }^{1} \mathrm{H}$ NMR spectrum of $\mathbf{2} \mathbf{a}$ is shown in Figure 1.

\section{Removal of Trithiocarbonate (2b)}

Modified PS 2a (3.03 g), tributylstannane (5.24 g), AIBN (0.39 g) and toluene (20 $\mathrm{mL})$ were added to a three-neck flask. The flask was purged with argon (20 min) three times and heated in an oil bath at $70{ }^{\circ} \mathrm{C}$ for $3 \mathrm{~h}$. After the mixture was cooled to room temperature, it was concentrated by rotary evaporation. The concentrated solution was poured into methanol to obtain the product $\mathbf{2 b}$. The product was dried at $50{ }^{\circ} \mathrm{C}$ under vacuum $\left(=10^{-3}\right.$ Torr $)$.

\section{Synthesis of PS-NH2 (2c)}

Modified PS 2b (1.35 g), hydrazine hydrate (0.34 g) and DMF (25 mL) were added to a three-neck flask. The reaction was carried out with stirring at $80{ }^{\circ} \mathrm{C}$ for $12 \mathrm{~h}$ in the protection of argon. The mixture was added into methanol. The precipitate was washed with deionized water and then with brine, and its color changed from yellow to white. Finally, the product $\mathbf{2 c}$ was obtained. The chemical structure of $\mathbf{2 a}, \mathbf{2 b}$ and $\mathbf{2 c}$ was characterized by ${ }^{1} \mathrm{H}$ NMR, and the spectra are shown in Figure 1. 


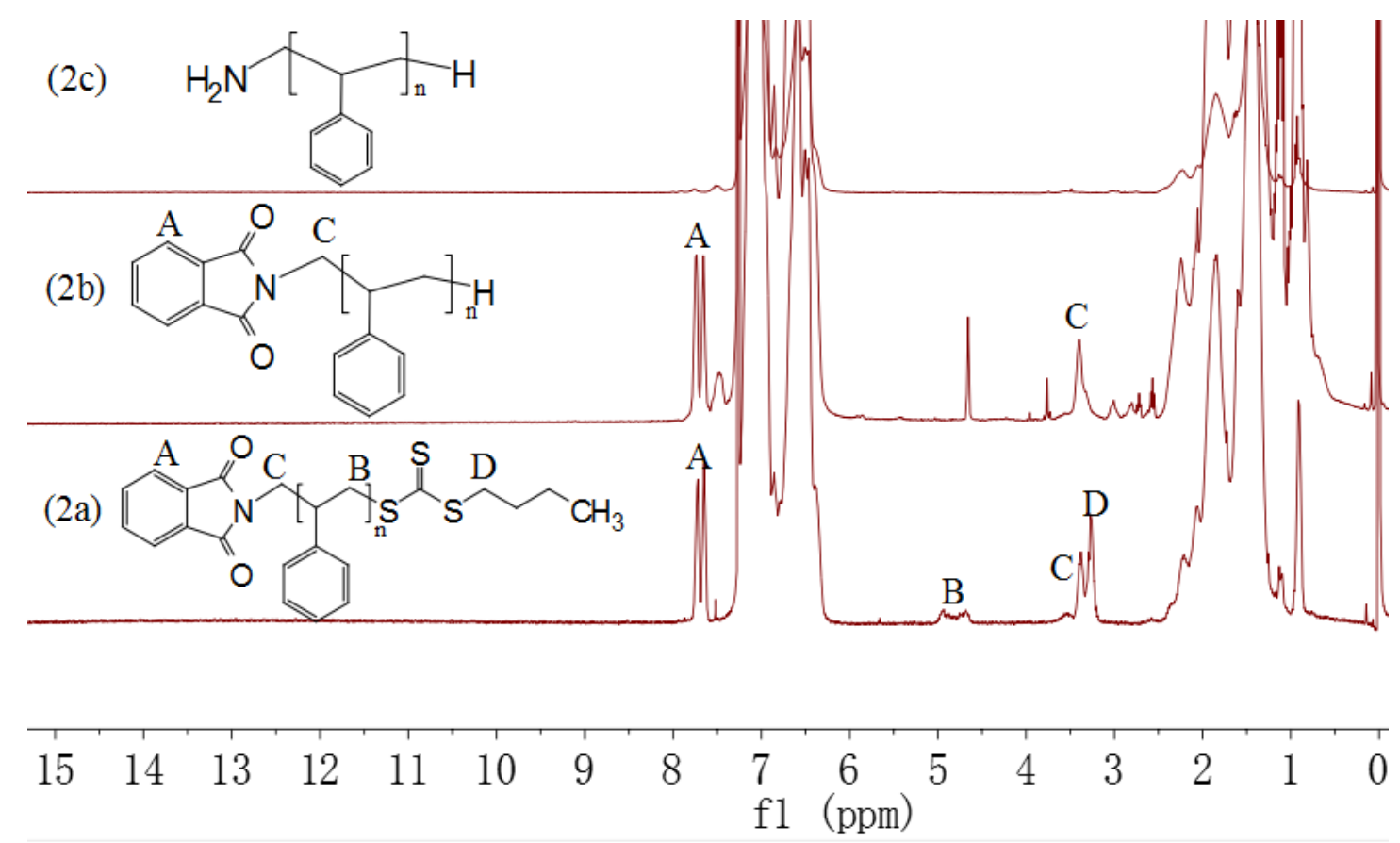

Figure 1. ${ }^{1} \mathrm{H}$ NMR spectra of $\mathbf{2 a}, \mathbf{2 b}$ and $\mathbf{2 c}$; all bands have been characterized in previous papers $^{[15]}$.

2.2.2 Synthesis of $\mathrm{H}_{2} \mathrm{~N}-\mathrm{PS}-\mathrm{NH}_{2}$ by atom transfer radical polymerization (ATRP)

\section{Synthesis of PS via ATRP (3a)}

The synthesis of PS via ATRP was carried out following a previous paper ${ }^{[16]} \cdot \mathrm{CuBr}$ (0.83 g), styrene (15 g), 2,2'-bipyridine (1.78 g) and N-(bromomethyl)phthalimide (2.35 g) were added into a three-neck flask. The flask was purged with argon (20 min) three times and was then heated in an oil bath at $110^{\circ} \mathrm{C}$ for various durations $(1.5,3 \mathrm{~h})$. The mixture was cooled to room temperature, diluted with THF $(25 \mathrm{~mL})$, and passed through a neutral alumina column to remove the copper catalyst. Then, the product was precipitated from methanol and dried under vacuum $\left(=10^{-3}\right.$ Torr $)$. 
A mixture of potassium phthalimide $(2.13 \mathrm{~g})$, PS 3a $(2.51 \mathrm{~g})$ and DMF $(30 \mathrm{~mL})$ was heated at $80{ }^{\circ} \mathrm{C}$ for $12 \mathrm{~h}$ under argon. Then, the mixture was added to water, and the product $3 b$ was prepared by filtration ${ }^{[17]}$.

\section{Synthesis of $\mathrm{H}_{2} \mathrm{~N}-\mathrm{PS}-\mathrm{NH}_{2}$ (3c)}

Product 3b (1.83 g), hydrazine hydrate (1.05 g) and DMF (25 mL) were added to a three-neck flask. The mixture was stirred at $80{ }^{\circ} \mathrm{C}$ for $16 \mathrm{~h}$ under argon. The mixture was added to methanol, and the precipitate was washed with deionized water and brine. Then, $\mathrm{H}_{2} \mathrm{~N}-\mathrm{PS}-\mathrm{NH}_{2} \mathbf{3 c}$ was obtained. The chemical structure of $\mathbf{3 a}, \mathbf{3 b}$ and $\mathbf{3} \mathbf{c}$ was characterized by ${ }^{1} \mathrm{H}$ NMR, and the spectra are shown in Figure 2.

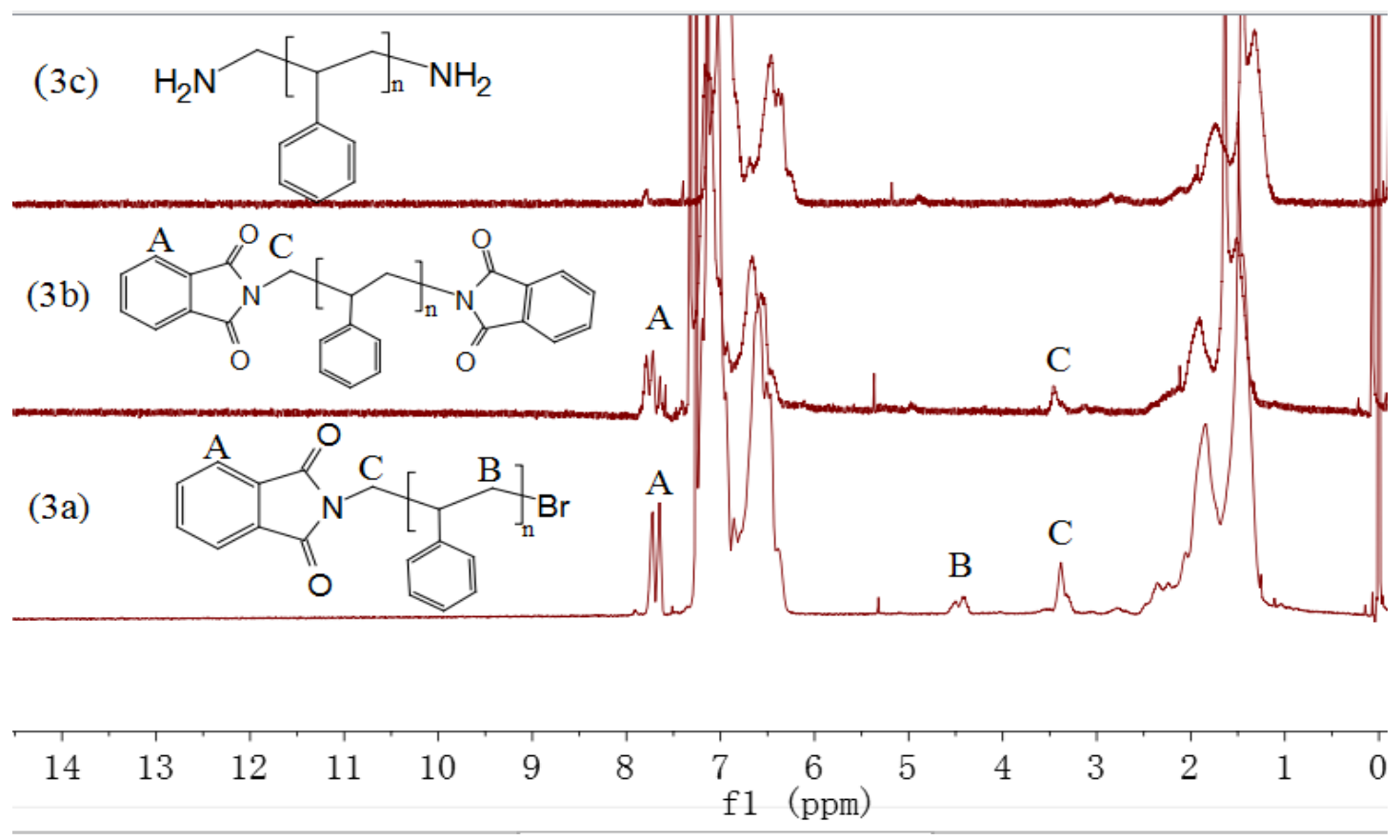

Figure 2. ${ }^{1} \mathrm{H}$ NMR spectra of 3a, 3b and 3c; A: Ar-H, B: Ph-CH-Br, C: phthalimide$\mathrm{CH}_{2}$.

\subsubsection{Synthesis of CDs- $\mathrm{SO}_{3} \mathrm{H}$}

Citric acid $(8.01 \mathrm{~g})$ was added to deionized water $(100 \mathrm{~mL})$. The mixture was sonicated and transferred to a hydrothermal kettle. The reaction was carried out at 200 
${ }^{\circ} \mathrm{C}$ for $5 \mathrm{~h}$. The mixture was cooled to room temperature and centrifugated at 10000 rpm for $20 \mathrm{~min}$. The supernatant was mixed with sulfanilic acid (1.25 g). The ultrasonic dispersion was uniformly placed in a hydrothermal kettle at $135^{\circ} \mathrm{C}$ for $5 \mathrm{~h}$. After being cooled to room temperature, the mixture was purified in a dialysis bag (500-1000D) for $48 \mathrm{~h}$ and lyophilized for $24 \mathrm{~h}$. Finally, a reddish brown solid (CDs-SO $\left.{ }_{3} \mathrm{H}\right)$ was obtained.

\subsection{Characterization}

${ }^{1} \mathrm{H}$ NMR and ${ }^{13} \mathrm{C}$ NMR measurements were conducted on a Bruker-AVANCE III $400 \mathrm{M}$ spectrometer using $\mathrm{CDCl}_{3}$ as the solvent.

Gel permeation chromatography (GPC) analyses were performed on a Waters 1515 instrument equipped with a MIXED 7.5×50 mm PL column, two MIXED-C 7.5×300 mm columns and a differential refractive index detector. Tetrahydrofuran (THF, HPLC grade) was used as the eluent at $35^{\circ} \mathrm{C}$ with a flow rate of $1 \mathrm{~mL} \mathrm{~min}{ }^{-1}$.

The O/W interfacial tension was measured by a KRÜSS DSA25 using the pendant drop method. $\mathrm{CDs}_{-} \mathrm{SO}_{3} \mathrm{H}(10 \mathrm{mg} / \mathrm{mL}, \mathrm{pH}=3,9), \mathrm{CNCs}^{-O S O}{ }_{3} \mathrm{H}(10 \mathrm{mg} / \mathrm{mL}, \mathrm{pH}=2$, $3,4,5,6,9)$ and GOs-SO $\mathrm{SH}_{3} \mathrm{H}(10 \mathrm{mg} / \mathrm{mL}, \mathrm{pH}=2,3,4,5,6,9)$ were added to deionized water as the aqueous phase, and $\mathrm{PS}_{-} \mathrm{NH}_{2}(1 \mathrm{mg} / \mathrm{mL})$ and $\mathrm{H}_{2} \mathrm{~N}-\mathrm{PS}-\mathrm{NH}_{2}(1 \mathrm{mg} / \mathrm{mL})$ were dissolved in toluene as the oil phase. When the aqueous droplet contacted the oil phase, the interfacial tension was measured and the time was marked as $0 \mathrm{~s}$. The intervals of the subsequent tests were every $15 \mathrm{~s}$ in the first $1 \mathrm{~min}$ and every $30 \mathrm{~s}$ after that. The experiments were carried out at $25^{\circ} \mathrm{C}$.

\subsection{Molecular dynamics (MD) simulation}


MD methods were used to simulate the interface between $\mathrm{H}_{2} \mathrm{~N}-\mathrm{PS}-\mathrm{NH}_{2}$ in the toluene phase and $\mathrm{CDs}-\mathrm{SO}_{3} \mathrm{H}$ in the water phase. The molecular model used in this study is illustrated in Figure 3, which is a large periodic unit cell with dimensions of $100 \AA \times$ $100 \AA \times 124 \AA$. In each unit cell, there are $19 \mathrm{H}_{2} \mathrm{~N}-\mathrm{PS}-\mathrm{NH}_{2}$ molecules, $19 \mathrm{CDs}-\mathrm{SO}_{3} \mathrm{H}$ molecules, 2000 toluene molecules and $10000 \mathrm{H}_{2} \mathrm{O}$ molecules. To simplify the model, we used positively charged $\mathrm{NH}_{3}-\left(\mathrm{CH}_{2}-\mathrm{CHC}_{6} \mathrm{H}_{5}\right)_{6}-\mathrm{NH}_{3}{ }^{2+}$ to represent the $\mathrm{H}_{2} \mathrm{~N}-\mathrm{PS}-\mathrm{NH}_{2}$ molecules. We also used $\mathrm{C}_{60}$ spheres to simulate quantum dots; therefore, the CDs$\mathrm{SO}_{3} \mathrm{H}$ are represented by negatively charged $\mathrm{C}_{60}-\left(\mathrm{SO}_{3}{ }^{-}\right)_{7}$. Both the toluene and the water phase were set to be electronically neutral by adding counter ions of $\mathrm{Cl}^{-}$and $\mathrm{H}_{3} \mathrm{O}^{+}$. These two phases were sandwiched by two layers of graphene, and a vacuum space of $24 \AA$ was added between the graphene layers to minimize electrostatic interactions between neighboring images in the z-direction.

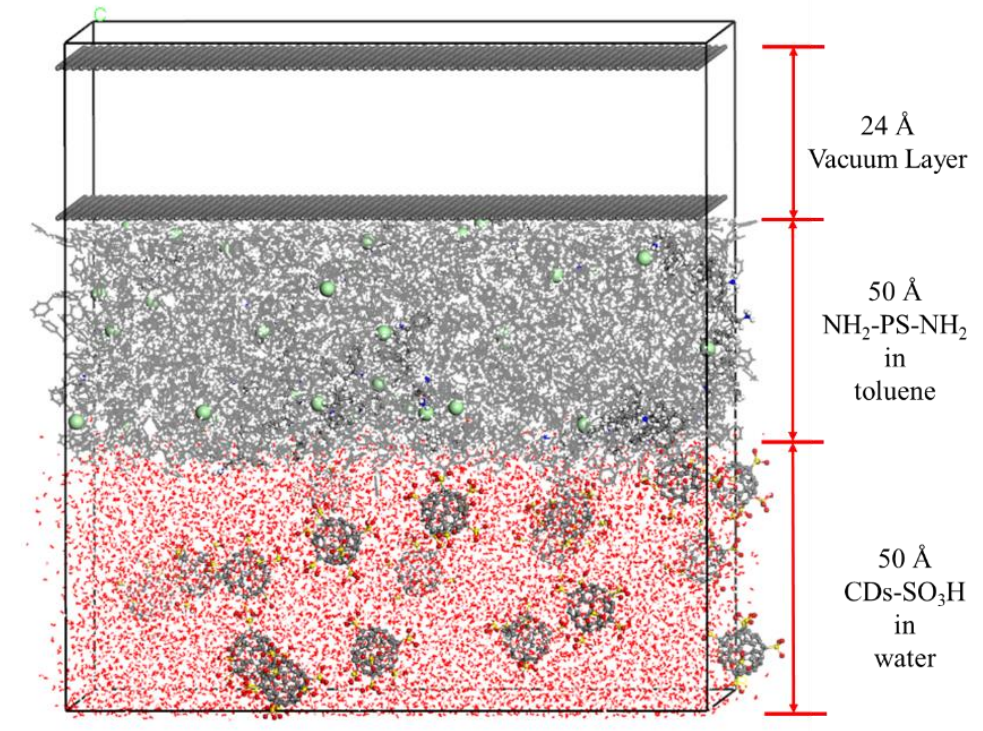

Figure 3. Model used in the MD simulations.

MD simulations were performed in the constant-volume and constant-temperature (NVT) ensemble with a Nosé-Hoover thermostat at $298 \mathrm{~K}^{[18]}$. A cutoff radius of 15.5 
$\AA$ and time step of 1 fs were used. The universal forcefield was used in this work ${ }^{[19]}$. During the simulations, the graphene layers were fixed.

\section{Results and Discussion}

The molecular weight and polydispersity (PDI) of PS- $\mathrm{NH}_{2}$ and $\mathrm{H}_{2} \mathrm{~N}-\mathrm{PS}-\mathrm{NH}_{2}$ are summarized in Table 1. The gravimetric conversion rate of aminated PS increased with the reaction time, and the PDI was well controlled.

Table 1. Molecular weights and polydispersity of aminated PS.

\begin{tabular}{|c|c|c|c|c|c|c|c|}
\hline & {$[\mathrm{St}] /[\mathrm{I}]$} & $\begin{array}{l}\text { Time } \\
\text { (h) }\end{array}$ & $\begin{array}{l}\text { Conv. } \\
(\%)\end{array}$ & $\begin{array}{c}\mathrm{M}_{\mathrm{n}}^{\text {Calc }} \\
\text { (Daltons) }\end{array}$ & $\begin{array}{l}\mathrm{M}_{\mathrm{n}}^{\mathrm{GPC}} \\
\text { (Daltons) }\end{array}$ & $\begin{array}{c}\mathrm{M}_{\mathrm{w}}^{\mathrm{GPC}} \\
\text { (Daltons) }\end{array}$ & PDI \\
\hline PS-NH 2 & 33.16 & 4 & 7.93 & 610 & 518 & 622 & 1.20 \\
\hline PS-NH 2 & 33.16 & 8 & 41.05 & 1752 & 2127 & 2528 & 1.21 \\
\hline PS-NH 2 & 33.16 & 12 & 65.82 & 2606 & 2970 & 3611 & 1.23 \\
\hline PS-NH 2 & 33.16 & 24 & 77.61 & 3013 & 3256 & 3920 & 1.20 \\
\hline $\mathrm{H}_{2} \mathrm{~N}-\mathrm{PS}-\mathrm{NH}_{2}$ & 14.71 & 1.5 & 47.15 & 961 & 931 & 1138 & 1.22 \\
\hline $\mathrm{H}_{2} \mathrm{~N}-\mathrm{PS}-\mathrm{NH}_{2}$ & 14.71 & 3 & 78.65 & 1443 & 2371 & 2844 & 1.20 \\
\hline
\end{tabular}

$\mathrm{M}_{\mathrm{n}}^{\text {Calc }}=\frac{[s t]}{[!]} \times$ Conv $\times 104+($ molecular weight of RAFT or ATRP agent $)$.

Three NPs, CDs- $\mathrm{SO}_{3} \mathrm{H}, \mathrm{CNCs}-\mathrm{OSO}_{3} \mathrm{H}$ and GOs-SO ${ }_{3} \mathrm{H}$, were used to interact with PS- $\mathrm{NH}_{2}$ and $\mathrm{H}_{2} \mathrm{~N}-\mathrm{PS}-\mathrm{NH}_{2}$ and form the assembly of NPs/surfactants.

By adjusting the $\mathrm{pH}$ of the aqueous phase toward acidity, the amino groups of PS underwent protonation $\left(-\mathrm{NH}_{3}{ }^{+}\right)$, while the sulfonate groups $\left(-\mathrm{SO}_{3}{ }^{-}\right)$and sulfate groups $\left(-\mathrm{OSO}_{3}{ }^{-}\right)$underwent deprotonation. The positively charged PS in the toluene phase interacted with the negatively charged NPs in the aqueous phase, resulting in a high concentration of $\mathrm{NP}$-surfactants at the interface and a low $\mathrm{O} / \mathrm{W}$ interfacial tension. 
In order to investigate the effect of $\mathrm{pH}$ on the interfacial activity of $\mathrm{NP}$-surfactants, a series of $\mathrm{CNC}-\mathrm{OSO}_{3} \mathrm{H}$ aqueous solutions $(10 \mathrm{mg} / \mathrm{mL}, \mathrm{pH}=2,3,4,5,6,9)$ were prepared to mix with a toluene solution. The $\mathrm{O} / \mathrm{W}$ interfacial tension between $\mathrm{CNC}$ $\mathrm{OSO}_{3} \mathrm{H}$ aqueous solutions $(\mathrm{pH}=3$ ) and pure toluene was approximately $35 \mathrm{mN} / \mathrm{m}$, which is close to the interfacial tension of water/toluene, indicating that $\mathrm{CNCs}-\mathrm{OSO}_{3} \mathrm{H}$ alone had no interfacial activity, as shown in Figure 4(e). When amino-terminated PS (1 $\mathrm{mg} / \mathrm{mL}$ ) was added to the toluene solution, the interfacial tension decreased significantly with the decrease in $\mathrm{pH}$, indicating that the $\mathrm{CNCs}^{-} \mathrm{OSO}_{3} \mathrm{H}$ and the polymers arranged as NPs/surfactants via electrostatic interaction at the $\mathrm{O} / \mathrm{W}$ interface. In the case of the $\mathrm{CNCs}-\mathrm{OSO}_{3} \mathrm{H}$ and $\mathrm{H}_{2} \mathrm{~N}-\mathrm{PS}-\mathrm{NH}_{2}\left(M_{w}=1.1 \mathrm{k}\right)$, the interfacial tension was lowered to $5.36 \mathrm{mN} / \mathrm{m}$ at $\mathrm{pH}=3$. A considerable decline in $\mathrm{O} / \mathrm{W}$ interfacial tension could be observed when the $\mathrm{pH}$ decreased from 6 to 5 , as amino groups protonated in the presence of an increasing amount of $\mathrm{H}^{+}$. However, as the $\mathrm{pH}$ decreased from 3 to 2 , the $\mathrm{O} / \mathrm{W}$ interfacial tension increased as a result of the suppression of the dissociation of $-\mathrm{SO}_{3} \mathrm{H}$. Similar phenomena could be observed in the compounding of the CNCs$\mathrm{OSO}_{3} \mathrm{H}$ and $\mathrm{PS}-\mathrm{NH}_{2}$ (Figure $4(\mathrm{a}-\mathrm{d})$ ). The $\mathrm{O} / \mathrm{W}$ interfacial tension of the $\mathrm{GOs}_{-} \mathrm{SO}_{3} \mathrm{H}$ with aminated PS at different $\mathrm{pH}$ values was also observed (shown in Supporting Information). 

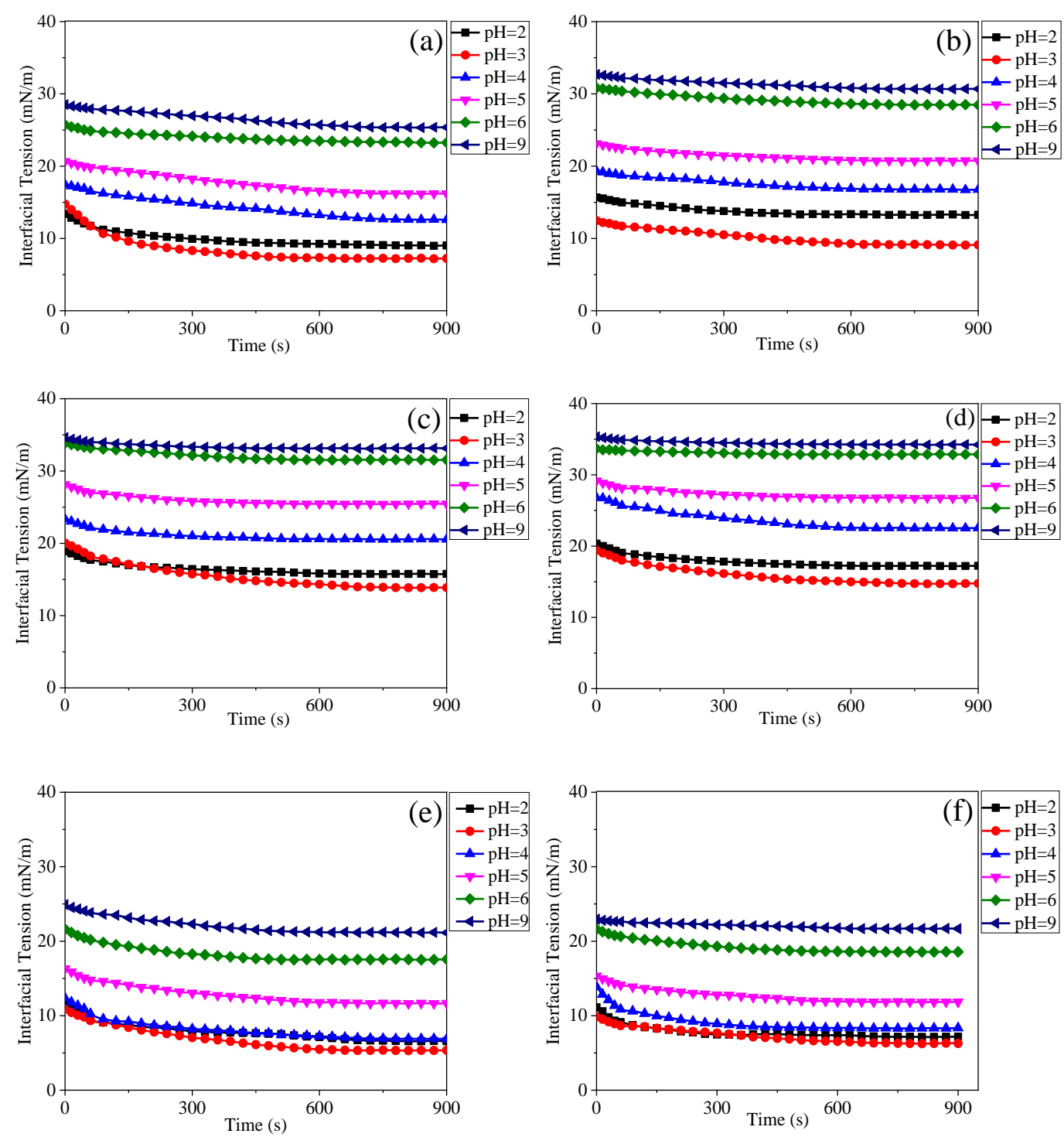

Figure 4. Aminated PS $(1 \mathrm{mg} / \mathrm{mL})$ compounding with $\mathrm{CNCs}^{-} \mathrm{OSO}_{3} \mathrm{H}(10 \mathrm{mg} / \mathrm{mL})$ at various pH. (a) PS-NH $2\left(M_{w}=0.6 \mathrm{k}\right)$; (b) $\mathrm{PS}^{-N_{2}}\left(M_{w}=2.5 \mathrm{k}\right)$; (c) $\mathrm{PS}_{2}-\mathrm{NH}_{2}\left(M_{w}=3.5\right.$ k); (d) PS-NH $2\left(M_{w}=3.9\right.$ k); (e) $\mathrm{H}_{2} \mathrm{~N}-\mathrm{PS}-\mathrm{NH}_{2}\left(M_{w}=1.1 \mathrm{k}\right)$; (f) $\mathrm{H}_{2} \mathrm{~N}-\mathrm{PS}-\mathrm{NH}_{2}\left(M_{w}=2.8\right.$ $\mathrm{k})$.

The results indicate that the $\mathrm{pH}$ of the aqueous solutions exerted a significant effect on the formation rate and interfacial activity of $\mathrm{NP}-$ surfactants. At $\mathrm{pH}=9$, amine groups were rarely protonated, and their interaction with negatively charged groups on the NPs through the electrostatic force was not intensive, thus failing to exhibit high 
interfacial activity. As the $\mathrm{pH}$ decreased, the protonation of amine groups increased dramatically, resulting in a strengthening interaction between positively charged surfactants and negatively charged NPs. NPs/surfactants assembled and deformed the $\mathrm{O} / \mathrm{W}$ interface, and the interfacial tension decreased. Meanwhile, it can be observed that the $\mathrm{O} / \mathrm{W}$ interfacial tension reached a minimum at $\mathrm{pH}=3$.

The reason for this may be that, although the ratio of primary amino protonation at $\mathrm{pH}=2$ is higher than that at $\mathrm{pH}=3$, the lower $\mathrm{pH}$ also inhibits the ionization of negatively charged groups in NPs partially combined with $\mathrm{H}^{+}$rather than $\mathrm{NH}_{3}^{+}$, leading to a slight decrease in interfacial activity, as the $\mathrm{pKa}$ of methanesulfonic acid ranged from 2.4 to 2.5 .

Similarly, the number of amino groups and the molecular weight of the polymers also have a significant influence on the interfacial tension. $\mathrm{PS}_{-\mathrm{NH}_{2}}\left(M_{w} \approx 0.6 \mathrm{k}, 2.5 \mathrm{k}, 3.5\right.$ $\mathrm{k}, 3.9 \mathrm{k})$ and $\mathrm{H}_{2} \mathrm{~N}-\mathrm{PS}-\mathrm{NH}_{2}\left(M_{w} \approx 1.1 \mathrm{k}, 2.8 \mathrm{k}\right)$ also reduced the $\mathrm{O} / \mathrm{W}$ interfacial tension with NPs $\left(\mathrm{CDs}-\mathrm{SO}_{3} \mathrm{H}, \mathrm{CNCs}-\mathrm{OSO}_{3} \mathrm{H}, \mathrm{GOs}-\mathrm{SO}_{3} \mathrm{H}\right)$ in the aqueous phase at $\mathrm{pH}=3$, as shown in Figure 5.

$\mathrm{PS}^{-\mathrm{NH}_{2}}\left(M_{w} \approx 0.6 \mathrm{k}\right)$ reduced the $\mathrm{O} / \mathrm{W}$ interfacial tension to approximately $6 \mathrm{mN} / \mathrm{m}$, interacting with $\mathrm{CDs}-\mathrm{SO}_{3} \mathrm{H}$. Similar behaviors had been observed in the interaction between $\mathrm{H}_{2} \mathrm{~N}-\mathrm{PS}-\mathrm{NH}_{2}\left(M_{w} \approx 1.1 \mathrm{k}\right)$ and $\mathrm{CDs}-\mathrm{SO}_{3} \mathrm{H}$, and the $\mathrm{O} / \mathrm{W}$ interfacial tension was reduced to approximately $4.5 \mathrm{mN} / \mathrm{m}$. $\mathrm{H}_{2} \mathrm{~N}-\mathrm{PS}-\mathrm{NH}_{2}$ also exhibited a better performance than PS-NH 2 when $\mathrm{CNCs}-\mathrm{OSO}_{3} \mathrm{H}$ and $\mathrm{GOs}-\mathrm{SO}_{3} \mathrm{H}$ were used as NPs. 

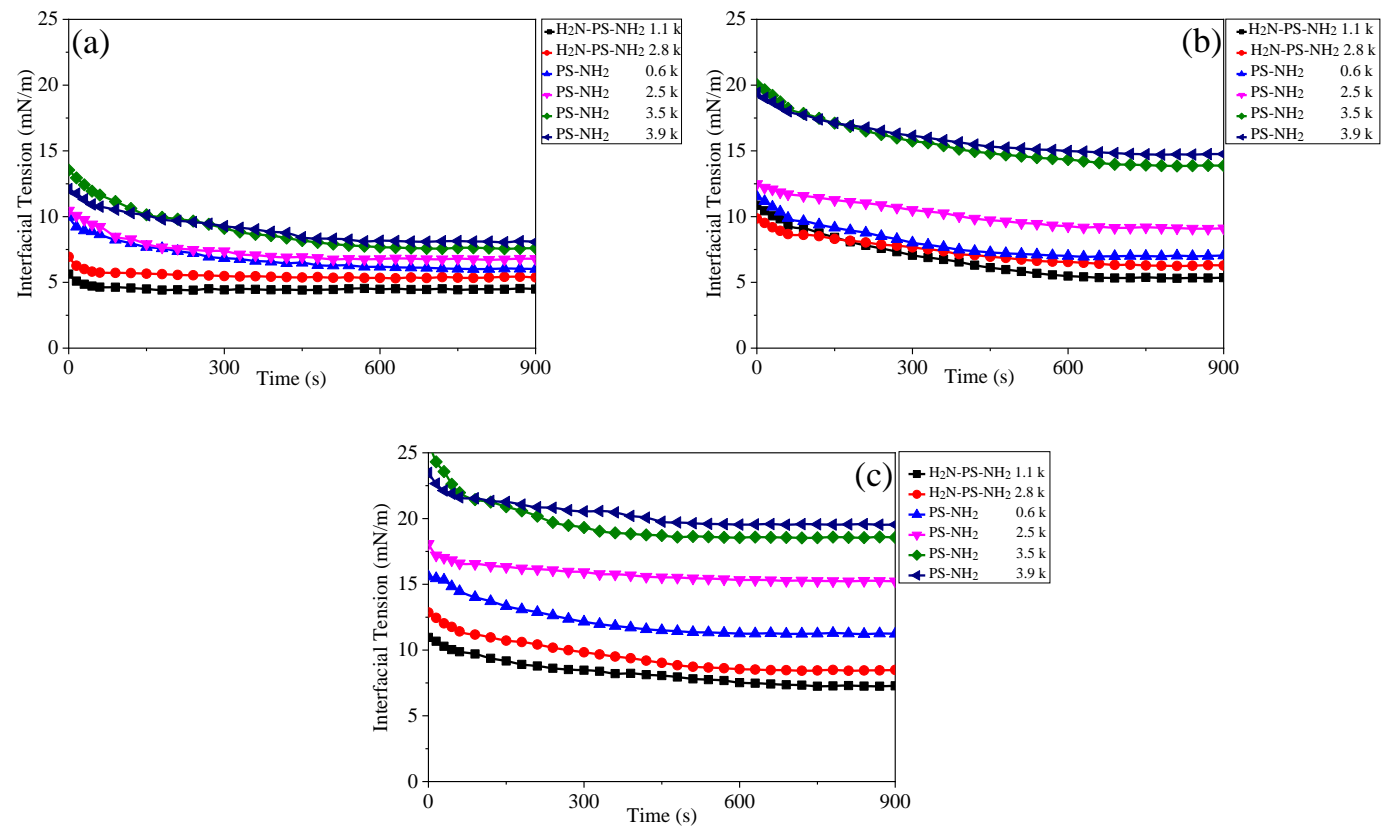

Figure 5. Aminated PS $(1 \mathrm{mg} / \mathrm{mL})$ compounding with $\mathrm{NPs}(10 \mathrm{mg} / \mathrm{mL})$ at $\mathrm{pH}=3$ : (a)

CDs- $\mathrm{SO}_{3} \mathrm{H}$; (b) CNCs-OSO${ }_{3} \mathrm{H}$; (c) GOs- $\mathrm{SO}_{3} \mathrm{H}$.

The percentage of the amine group in PS- $\mathrm{NH}_{2}$ can be calculated using formula $(1)^{15}$, in which $m$ is the molar mass of the monomer unit and $M_{n}$ is the molecular weight of PS-NH 2 determined by GPC.

$$
\left[\mathrm{NH}_{2}\right]=\frac{\frac{1}{M_{n}}}{m} \times 10^{6}
$$

As the molecular weight increases, the percentage of amine groups decreases. In the case of PS- $\mathrm{NH}_{2}(0.6 \mathrm{k})$, the percentage of the amine groups is $18.56 \mu \mathrm{g} / \mathrm{g}$; as for PS$\mathrm{NH}_{2}(3.9 \mathrm{k})$, this figure decreases to $2.95 \mu \mathrm{g} / \mathrm{g}$. Therefore, this demonstrates that the higher the content of amino groups in aminated PS, the lower the $\mathrm{O} / \mathrm{W}$ interfacial tension. In addition, although $\mathrm{H}_{2} \mathrm{~N}-\mathrm{PS}-\mathrm{NH}_{2}\left(M_{w} \approx 1.1 \mathrm{k}\right)$ has a higher $M_{n}$ than $\mathrm{PS}-\mathrm{NH}_{2}$ $\left(M_{w}=0.6 \mathrm{k}\right)$, the former can prevent the deformation of the drop while interacting with $\mathrm{CDs}_{-} \mathrm{SO}_{3} \mathrm{H}$, thereby reaching a lower $\mathrm{O} / \mathrm{W}$ interfacial tension ${ }^{[9]}$. 
The dimension of NPs $\left(\mathrm{CDs}-\mathrm{SO}_{3} \mathrm{H}\right.$ of zero dimensions, $\mathrm{CNCs}-\mathrm{OSO}_{3} \mathrm{H}$ of one dimension, $\mathrm{GOs}-\mathrm{SO}_{3} \mathrm{H}$ of two dimensions) also affected the $\mathrm{O} / \mathrm{W}$ interfacial tension, as shown in Figure 6.
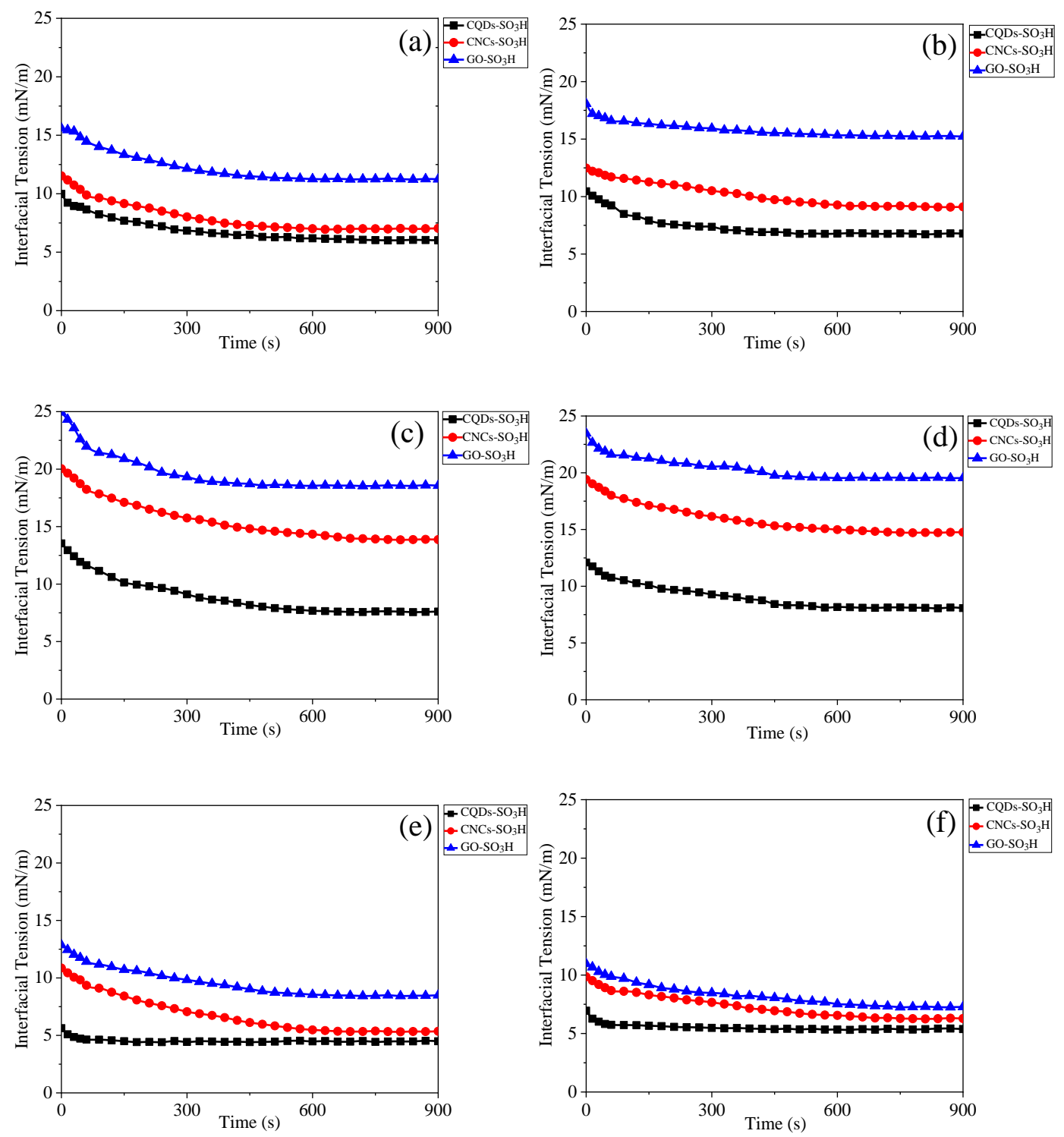

Figure 6. NPs $(10 \mathrm{mg} / \mathrm{mL})$ compounding with aminated $\mathrm{PS}(1 \mathrm{mg} / \mathrm{mL})$ at $\mathrm{pH}=3$. (a)

PS-NH $2\left(M_{w}=0.6 \mathrm{k}\right)$; (b) PS-NH $2\left(M_{w}=2.5 \mathrm{k}\right)$; (c) PS-NH $2\left(M_{w}=3.5 \mathrm{k}\right)$; (d) PS-NH $\left(M_{w}=3.9 \mathrm{k}\right) ;(\mathrm{e}) \mathrm{H}_{2} \mathrm{~N}-\mathrm{PS}-\mathrm{NH}_{2}\left(M_{w}=1.1 \mathrm{k}\right)$; (f) $\mathrm{H}_{2} \mathrm{~N}-\mathrm{PS}-\mathrm{NH}_{2}\left(M_{w}=2.8 \mathrm{k}\right)$. 
The formation of $\mathrm{CD}-\mathrm{SO}_{3} \mathrm{H} /$ surfactants appears faster than those of $\mathrm{CNC}$ $\mathrm{OSO}_{3} \mathrm{H} /$ surfactants and $\mathrm{GO}-\mathrm{SO}_{3} \mathrm{H} /$ surfactants. The former also performed better in the $\mathrm{O} / \mathrm{W}$ interfacial tension than the latter. These results reveal that NPs of various dimension had a different morphology at the $\mathrm{O} / \mathrm{W}$ interface in the presence of aminated PS. The spherical CDs- $\mathrm{SO}_{3} \mathrm{H}$ had a diameter of approximately $2.71 \mathrm{~nm}$; the rod-like CNCs-OSO 3 H had a diameter of 5-20 nm and a length of $100-200 \mathrm{~nm}$; and the lamellar GOs- $\mathrm{SO}_{3} \mathrm{H}$ had a diameter of $1.2-4.0 \mu \mathrm{m}$ and a thickness of $0.8-6.6 \mathrm{~nm}$. Considering the effect of NP dimension on the arrangement efficiency of NPs/surfactants at the interface, the $\mathrm{CDs}-\mathrm{SO}_{3} \mathrm{H}$ (0 dimension) had a more compacted structure with surfactants than the CNCs- $\mathrm{OSO}_{3} \mathrm{H}$ and $\mathrm{GOs}-\mathrm{SO}_{3} \mathrm{H}$.

To gain a better understanding of the interaction between NPs and aminated PS in the $\mathrm{O} / \mathrm{W}$ interface and their final assembly, a MD simulation was performed for a total time length of $100 \mathrm{ps}$ (video 1 in supporting files). The evolution of the structure of the phase interface over time can be observed in the snapshots shown in Figure 7. For clarity, only $\mathrm{H}_{2} \mathrm{~N}-\mathrm{PS}-\mathrm{NH}_{2}$ and $\mathrm{CD}-\mathrm{SO}_{3} \mathrm{H}$ molecules are shown, while solvent molecules are hidden. It can be found that when the time is $0 \mathrm{ps,} \mathrm{the} \mathrm{NPs} \mathrm{in} \mathrm{the} \mathrm{aqueous} \mathrm{phase}$ aggregated with each other, and only few moved to the interface.

With the increase in the simulation time, $\mathrm{H}_{2} \mathrm{~N}-\mathrm{PS}-\mathrm{NH}_{2}$ in toluene and $\mathrm{CDs}-\mathrm{SO}_{3} \mathrm{H}$ in the aqueous phase attracted each other by the electrostatic force, and more NPs moved to the interface and combined with $\mathrm{H}_{2} \mathrm{~N}-\mathrm{PS}-\mathrm{NH}_{2}$ to form NPs/surfactants. Eventually, it can be observed that both $\mathrm{H}_{2} \mathrm{~N}-\mathrm{PS}-\mathrm{NH}_{2}$ and $\mathrm{CD}-\mathrm{SO}_{3} \mathrm{H}$ molecules were concentrated on the phase interface and approached each other under the influence of the electrostatic 
attractions. At $100 \mathrm{ps}$, the assembly of $\mathrm{H}_{2} \mathrm{~N}-\mathrm{PS}-\mathrm{NH}_{2}$ and $\mathrm{CD}-\mathrm{SO}_{3} \mathrm{H}$ reached a thermodynamic equilibrium, driving by the electrostatic force, which indicates that these two substances have a strong tendency to arrange in an orderly aggregation in the $\mathrm{O} / \mathrm{W}$ interface.
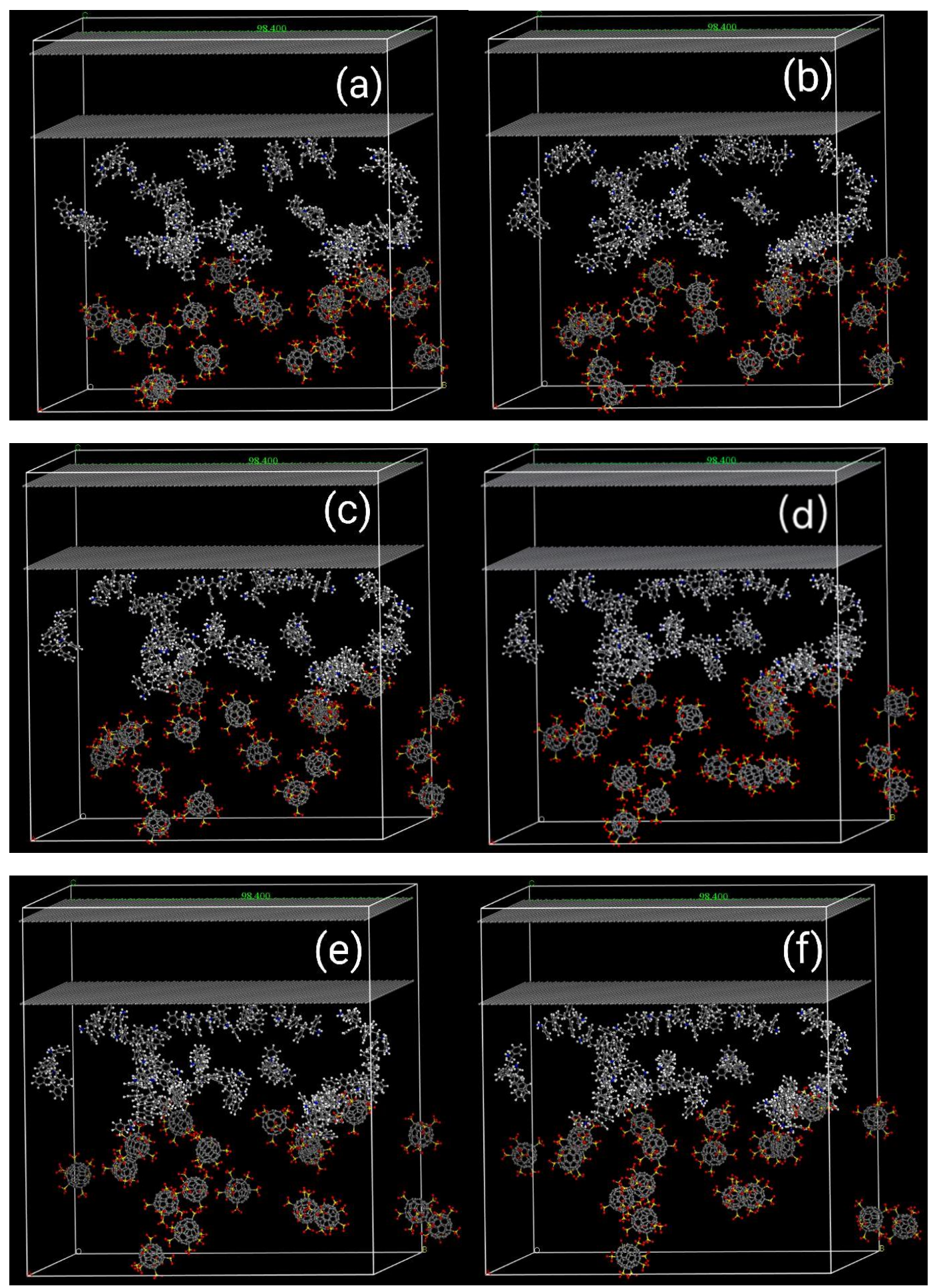
Figure 7. MD simulation of $\mathrm{H}_{2} \mathrm{~N}-\mathrm{PS}-\mathrm{NH}_{2}$ compounding with $\mathrm{CDs}-\mathrm{SO}_{3} \mathrm{H}$; (a) 0 ps; (b) 3 ps; (c) 10 ps; (d) 25 ps; (e) 50 ps; (f) 100 ps.

Results of the MD simulation should not be interpreted as a conclusion that the NPs/surfactants interface can be formed and reach an equilibrium state in a short time scale such as $100 \mathrm{ps}$. In fact, in the starting point ( $t=0 \mathrm{ps})$ of the MD simulations, NPs and surfactant molecules have already aggregated around the phase interface. Therefore, the MD simulation suggests that the system of the phase interface can return to the equilibrium state after a small perturbation. The MD simulation can serve as a proof of the thermodynamic stability of the NPs/surfactants interface but not a reflection of the dynamic process of phase interface formation in the macroscope time and length scale, the latter takes

\section{Conclusions}

In this study, PS- $\mathrm{NH}_{2}$ with different molecular weights was synthesized by RAFT followed by chemical modification. $\mathrm{H}_{2} \mathrm{~N}-\mathrm{PS}-\mathrm{NH}_{2}$ was prepared by ATRP and then modified by the Gabriel method. The factors determining the $\mathrm{O} / \mathrm{W}$ interfacial tension of the compounding between aminated polystyrene and nanoparticles include the $\mathrm{pH}$ of aqueous phase, molecular weight of aminated PS, the density of amine groups and NPs dimension. The grafting density of amine groups in polystyrene and the dimension of nanoparticles play important roles, other than the $\mathrm{pH}$ and the molecular weight of functionalized polymers suggested by previous works ${ }^{[7,9]}$, in adjusting the $\mathrm{O} / \mathrm{W}$ interfacial tension. The compounding of $\mathrm{H}_{2} \mathrm{~N}-\mathrm{PS}-\mathrm{NH}_{2}(1.1 \mathrm{k})$ with $\mathrm{CDs}-\mathrm{SO}_{3} \mathrm{H}$ at $\mathrm{pH}=$ 3 exhibited a highest efficiency to reduce the $\mathrm{O} / \mathrm{W}$ interfacial tension to $4.49 \mathrm{mN} / \mathrm{m}$, 
which is a significant improvement compared with previous results ${ }^{[5,7,20]}$. The results suggest that the density of amine groups has a positive correlation with the performance of aminated PS. NPs with a smaller dimension also contribute to the lowering of $\mathrm{O} / \mathrm{W}$ interfacial tension. The molecular simulation results of the evolution of the distribution of NPs and aminated PS at the O/W interface revealed that $\mathrm{CDs}-\mathrm{SO}_{3} \mathrm{H}$ and $\mathrm{H}_{2} \mathrm{~N}-\mathrm{PS}-$ $\mathrm{NH}_{2}$ reaching a distribution equilibrium within a considerably short time.

The fast and significant reduction in $\mathrm{O} / \mathrm{W}$ interfacial tension induced by NPs/surfactants assembly could be applied in both enhanced oil recovery and inkjet printing. Based on the result of this study, we plan to carry out a further research on both increasing the number of amino groups in PS and decreasing the size of CDs$\mathrm{SO}_{3} \mathrm{H}$, aiming at lowering the $\mathrm{O} / \mathrm{W}$ interfacial tension by more than an order of magnitude.

\section{Author Information}

\section{Corresponding Author}

Ling Lin

Email: cowbolinling@aliyun.com; Tel.: +86-28-83037306 (L.L)

\section{Acknowledgements}

This research was funded by the National Science and Technology Major Project (2017ZX05023003-002), College Students Innovative Entrepreneurial Training Plan Program of Sichuan Province (201910615077).The authors acknowledge ceshigo 
(www.ceshigo.com) for providing ${ }^{1} \mathrm{H}$ NMR, ${ }^{13} \mathrm{C}$ NMR and GPC testing. Computational resources were provided by the National Supercomputing Center in Shenzhen.

\section{Conflict of interest}

The authors declare no conflict of interest.

\section{References}

1. Böker, A.; He, J.; Russell, T. P.; Emrick, T. S., Self-assembly of nanoparticles at interfaces. Soft Matter 2007, 3 (10), 1231-1248.

2. Bresme, F.; Oettel, M., TOPICAL REVIEW: Nanoparticles at fluid interfaces. Journal of Physics Condensed Matter 2007, 19 (19), 3385-3391.

3. Lin, Y.; Skaff, H.; Emrick, T.; Dinsmore, A. D.; Russell, T. P., Nanoparticle assembly and transport at liquid-liquid interfaces. (Reports). Science 2003, 299 (5604), 226-229.

4. Liu, X.; Shi, S.; Li, Y.; Forth, J.; Wang, D.; Russell, T. P., Liquid Tubule Formation and Stabilization Using Cellulose Nanocrystal Surfactants. Angewandte Chemie 2017, 56 (41), 12594.

5. Larsson, K., Interfacial phenomena - Bioadhesion and Biocompatibility. Desalination 1980, 35 (1), $105-114$.

6. Murray, B. S., Interfacial rheology of food emulsifiers and proteins. Current Opinion in ColloidI nterface Science 2002, 7 (5), 426-431.

7. Jeirani, Z.; Mohamedjan, B.; Siali, B.; See, C. H.; Saphanuchart, W., Pre-prepared Microemulsion Flooding in Enhanced Oil Recovery: A Review. Liquid Fuels Technology 2014, 32 (2), 180-193.

8. Forth, J.; Liu, X.; Hasnain, J.; Toor, A.; Miszta, K.; Shi, S.; Geissler, P. L.; Emrick, T.; Helms, B. A.; Russell, T. P., Reconfigurable Printed Liquids. Advanced Materials 2018, 30 (16), e1707603.

9. Shi, S. W.; Russell, T. P., Nanoparticle Assembly at Liquid-Liquid Interfaces: From the Nanoscale to Mesoscale. Advanced Materials 2018, 30 (44).

10. Huang, C.; Sun, Z.; Cui, M.; Liu, F.; Helms, B. A.; Russell, T. P., Structured Liquids with pH-Triggered Reconfigurability. Advanced Materials 2016, 28 (31), 6612-6618.

11. Chai, Y.; Lukito, A.; Jiang, Y.; Ashby, P. D.; Russell, T. P., Fine-Tuning Nanoparticle Packing at Water-Oil Interfaces Using Ionic Strength. Nano Letters 2017, 17 (10), acs.nanolett.7b03462. 12. Toor, A.; Lamb, S.; Helms, B.; Russell, T. P., Reconfigurable Microfluidic Droplets Stabilized by Nanoparticle Surfactants. Acs Nano 2018, 12 (3), 2365-2372.

13. Toor, A.; Helms, B. A.; Russell, T. P., Effect of Nanoparticle Surfactants on the Breakup of FreeFalling Water Jets during Continuous Processing of Reconfigurable Structured Liquid Droplets. Nano Letters, acs.nanolett.7b00556.

14. M, C.; Todd, E.; Russell, T. P., Stabilizing liquid drops in nonequilibrium shapes by the interfacial jamming of nanoparticles. Science 2013, 342 (6157), 460-463. 
15. Postma, A.; Davis, T. P.; Evans, R. A.; Li, G. X.; Moad, G.; O'Shea, M. S., Synthesis of well-defined polystyrene with primary amine end groups through the use of phthalimido-functional RAFT agents. Macromolecules 2006, 39 (16), 5293-5306.

16. Postma, A.; Davis, T. P.; Moad, G.; O'Shea, M. S., Approaches to phthalimido and amino endfunctional polystyrene by atom transfer radical polymerisation (ATRP). Reactive \& Functional Polymers 2006, 66 (1), 137-147.

17. Monge, S.; Giani, O.; Ruiz, E.; Cavalier, M.; Robin, J. J., A new route for the modification of halogen end groups to amino end-functionalized poly(tert-butyl acrylate)s. Macromolecular Rapid Communications 2007, 28 (23), 2272-2276.

18. Hoover, W. G., Canonical dynamics: Equilibrium phase-space distributions. Phys Rev A Gen Phys 1985, 31 (3), 1695-1697.

19. Rappe, A. K.; Casewit, C. J.; Colwell, K. S.; Goddard, W. A.; Skiff, W. M., UFF, a full periodic table force field for molecular mechanics and molecular dynamics simulations. J.Am.Chem.Soc 1992, 114 (25), 10024-10035. 